\title{
POLÍTICAS PÚBLICAS NO ÂMBITO DO EMPREENDEDORISMO FEMININO: PERSPECTIVAS DE EMPODERAMENTO
}

\section{PUBLIC POLICIES IN THE FIELD OF FEMALE ENTREPRENEURSHIP: EMPOWERMENT PERSPECTIVES}

\author{
Gustavo Pedroso Malavota* \\ Maria Natalina Cinegaglia** \\ Silvia Conceição Reis Pereira Mello***
}

Resumo: Sob uma perspectiva de empoderamento feminino, é possível destacar o crescimento do empreendedorismo como um movimento de emancipação feminina em muitos âmbitos, como o social, político e econômico. Tal progresso se pauta em associações de políticas sociais à políticas públicas por parte de instituições de relevância notável, como a Organização das Nações Unidas. De maneira análoga, percebe-se uma condição de coexistência entre a economia solidária e o avanço do empreendedorismo feminino, traçando assim um parâmetro de observação por termos colaborativos e cooperativos de desenvolvimento econômico.

Palavra-Chave: Empoderamento Feminino. Empreendedorismo. Gênero. Políticas Públcias. Agenda 2030.

Abstrat: Under the perspective of female empowerment it is possible do detach the growth of entrepreneurship as a movement of female emancipation in various spheres like social, political and economic. Such progress lays itself in associations of social policies and political policies by relevant institutions such as United Nations. Similarly it can be perceived a coexistence condition between solidarity economy and female entrepreunership progress being able to draw an observation pattern in colaborative and cooperative terms of economic development.

Keywords: Female Empowerment. Entrepreneurship. Gender. Public Policies. Agenda 2030.

\footnotetext{
*Mestranda do Programa de Pós-Graduação em Desenvolvimento Local do Centro Universitário Augusto Motta, Campus Bonsucesso, Rio de Janeiro, RJ, e-mail: gustavo@malavota.com.br

** Mestrando do Programa de Pós-Graduação em Desenvolvimento Local do Centro Universitário Augusto Motta, Campus Bonsucesso, Rio de Janeiro, RJ, e-mail: natalinac@gmail.com

*** Doutora em Medicina Veterinária, Professora do Programa de Pós-graduação em Desenvolvimento Local, Centro Universitário Augusto Motta, Rio de Janeiro, RJ e Pesquisadora da Fundação Instituto de Pesca do Estado do Rio de Janeiro e-mail: silviaqua@oul.com.br
} 


\section{INTRODUÇÃO}

A partir da Primeira Guerra Mundial, com a ausência da mão de obra masculina, que se encontrava em guerra, houve um progresso cronológico da posição crescente da mulher no mercado de trabalho. Tal momento definiu o ponto de não retorno das mulheres no mercado de trabalho.

No Brasil, as mulheres vêm tomando cada vez mais comandos, cargos e lugares na sociedade até então ocupados excepcionalmente pelos homens. Na última década, seguindo o padrão de outros países em desenvolvimento, a mulher brasileira vem se qualificando e ampliando cada vez mais a sua liderança.

Cada vez mais se valoriza as habilidades de liderança da mulher. Valores intrínsecos à maneira de trabalho feminino, como o trabalho em equipe, proatividade, cooperação e colaboração. O empreendedorismo feminino também entra em debate, sobretudo a partir da Agenda 2030 da ONU para o Desenvolvimento Sustentável. Tal agenda traz pontos, inscritos no Objetivo no 5 , que prevê o empoderamento feminino, através de medidas econômicas e da independência financeira, visando a igualdade de gênero e sempre destacando o empreendedorismo por sua característica emancipatória.

O planejamento também prevê o reconhecimento e a valorização do trabalho doméstico e assistencial não remunerados, buscando o compartilhamento de deveres domiciliares entre os gêneros e expondo à sociedade sua importância. Além disso, outra medida se pauta em garantir a participação feminina em cargos de liderança, reconhecendo a sua capacidade, independente do gênero.

E ainda a garantia de iguais recursos financeiros e à propriedade privada. Tais garantias são fundamentais para o empoderamento através da posição de empreendedora, instaurando os princípios de uma tradição que, nacionalmente, não eram anteriormente observados. Tal evolução pode ser observada em grande escala na última década, principalmente. 


\section{POLÍTICA PÚBLICA}

Por Lynn (1980), política pública define como um anexo de atos do governo que irão dar resultados exclusivos. Na visão de Peters (1986), é a adição de ações dos governos, que atuam inteiramente ou pelo meio de comissão e que interferem na vida da população. Para Dye (1984) política pública é o que o governo escolhe fazer ou não fazer.

Diferentes significados destacam o campo da política pública na solução de dificuldades. Críticos desses significados, que superestimam aspectos coerentes e procedimentais das políticas públicas, questionam que elas desconhecem o cerne da política pública, isto é, o encontro em torno de opiniões e negócios.

Pode-se ainda adicionar que, por reunirem o olhar na ação dos governos, esses significados abandonam a sua aparência conflituosa e os limites que cercam as decisões dos governos. Deixam também de fora possibilidades de auxílio que podem acontecer no meio dos governos e diferentes instituições e coligações sociais. No entanto significados de políticas públicas, ainda as minimalistas, conduzem o nosso olhar para o foco onde os choques em torno de méritos, prioridades e ideias crescem: os governos.

A política pública em comum e a política social de forma reservada é feita para várias áreas. Uma teoria geral da política pública implica a busca de abreviar conjeturas edificadas no campo da sociologia, da ciência política e da economia. As políticas públicas refletem na economia e nas sociedades, daí por que uma teoria de política pública carece também de elucidar as inter-relações entre Estado, política, economia e sociedade.

Pode-se dizer que Políticas públicas, nada mais é que um campo da ciência que coloca o governo em ação e que esta pode ser modificada quando necessário e possível propor mudanças no rumo das ações. O objetivo das políticas públicas onde o Governo coloca em práticas seus propósitos e planos eleitorais em programas efetivos, que produzirão mudanças na população.

As Políticas Públicas possuem modelagens próprias, embora seja convencionalmente um ramo da ciência política. Por último, políticas públicas, após 
esboçadas e estabelecidas, desdobram-se em planos, programas, formação da ideia, embasamentos de informações ou norma de ciência e pesquisas. Quando colocadas em atuação, são praticadas, tornando se submetidas a normas de acompanhamento e avaliação.

\section{EMPREENDEDORISMO FEMININO}

Atualmente, empreendedorismo é uma prática multidisciplinar, envolvendo ações econômicas, administradoras, psicológicas, entre outras, e significa colocar em prática uma ideia, fazer da construção de um grande feito, visando uma mudança ou inovação de algo, possuir iniciativa e buscar realizar novas realizações ou aperfeiçoar as já existentes, ou seja, para empreender é necessário idealizar, coordenar, aperfeiçoar e almejar a melhoria de negócios e projetos. Ainda assim, nem sempre foi visto dessa forma, apesar de ser uma prática antiga, o empreendedorismo sofreu diversas mudanças de significado ao longo da história das empresas.

Partindo disso, o termo empreendedor foi utilizado para aquele que apenas gerenciava grandes projetos de produção através da utilização dos recursos disponíveis. Para Cruz (2005) o clérigo - pessoa que era encarregada de obras arquitetônicas - era visto com um típico empreendedor na Idade Média. No século V a $\mathrm{XV}$, período onde se denominava a Idade Média, os empreendedores por questões de apenas lidar com gerenciamento de projetos, hoje são vistos como empreendedores que não se arriscaram nas suas decisões, não obstante, no século seguinte dá-se início a manifestação do termo "empreendedor". "A palavra "empreendedor" (entrepreuneur) foi utilizado pela primeira vez na linguagem francesa no início do século XVI, para designar os homens envolvidos na coordenação de operações militares." (CRUZ, 2005, p.23).

No entanto, é apenas no século XVII que os sentidos referentes ao termo passa ser parecido com o que conhecemos nos dias atuais.

Os diversos conceitos de empreendedorismo existentes não fazem distinção de gênero, visto que as características empreendedoras podem ser encontradas tanto em homens quanto em mulheres, ainda que suas primeiras definições contemplam quase exclusivamente 0 
público masculino. No entanto, nos dias atuais, é inegável o peso Feminino crescente na população economicamente ativa (PEA) e na atividade econômica, não só no Brasil, mas também em diversos países do mundo todo. (STROBINO, TEXEIRA, 2013, p. 60)

A mulher por muitos séculos foi vista como frágil e dependente do homem. Com o passar dos anos, a mulher vem mostrando sua força de mercado econômico, com isso tem-se visto o crescimento de mulheres empreendedoras, fazendo com que esta ação não traga apenas independência financeira, mas principalmente satisfação e autoestima. O gráfico abaixo mostra o crescimento do empreendedorismo feminino no Brasil. Gráfico 1: Taxas específicas e estimativas em milhões do número de
empreendedores por estágio e sexo no Brasil em 2017

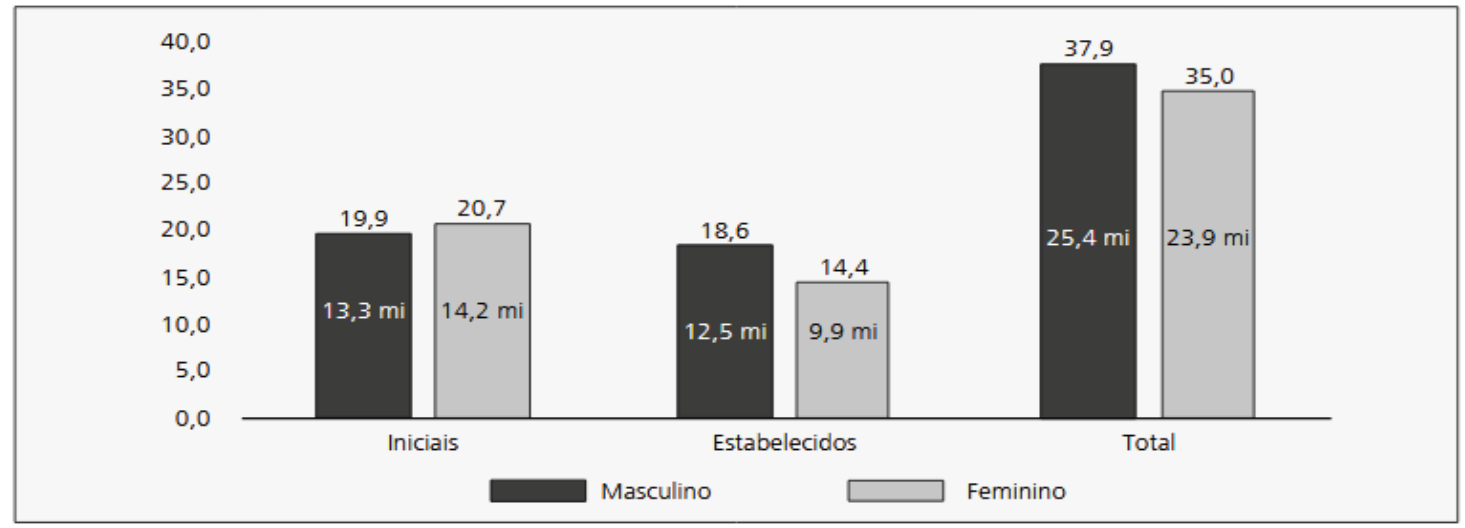

Fonte: GEM Brasil 2017

Pelo gráfico, verifica-se um crescimento das empreendedoras iniciais. No gráfico abaixo, nota-se um estabelecimento na equidade do número de empreendedores por gêneros. Tendo sua maior disparidade observada nos empreendimentos já estabelecidos. Percebido na diferença de 2,6 milhões a mais de empreendedores do sexo masculino. No entanto, o número de empreendedores do sexo feminino no estágio inicial se apresenta maior. 


\section{Imagem 2: Evolução no número de empreendedores individuais por sexo no} Brasil

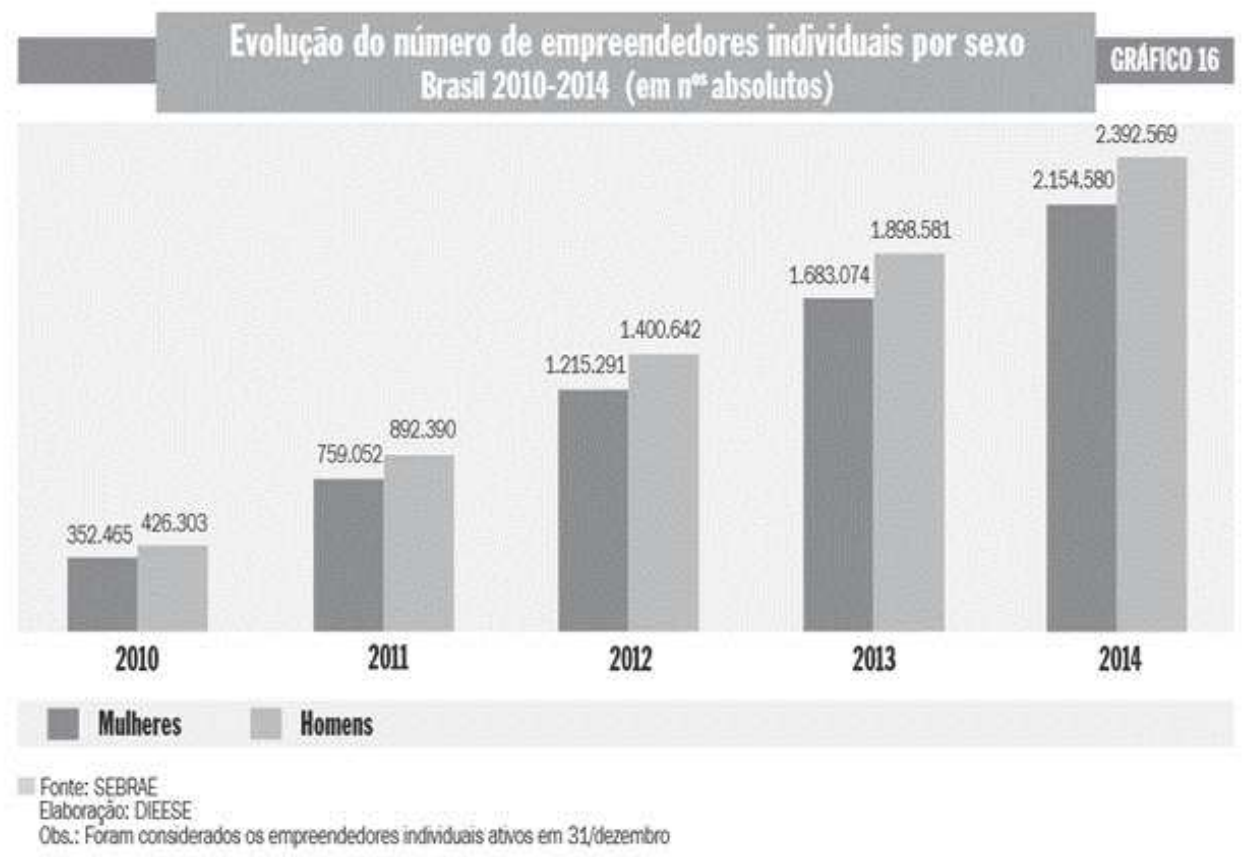

Os gráficos mostram um crescimento acentuado de empreendedorismo feminino. Em 201, eram 352 mil empreendedoras mulheres individuais ou em estágio inicial, junto a 426 mil homens. Até 2014, o crescimento foi até mais de dois milhões de empreendedores e empreendedoras, com os homens ainda ligeiramente à frente.

O Brasil atingiu, de acordo com o Global Entrepreneurship Monitor (GEM), o valor total de 14,2 milhões de mulheres empreendendo em estágio inicial, ultrapassando o número total de empreendedores homens em estágio inicial, que totalizaram 13,3 milhões.

Tais números demonstram uma tendência de equidade entre gêneros, impulsionada pelos pontos da Agenda 2030 (ORGANIZAÇÃO DAS NAÇÕES UNIDAS, 2015), que em seu Objetivo 5 trata do empoderamento da mulher.

Existem inúmeras maneiras de inserir a mulher na sociedade de maneira equivalente e justa, respeitando os contrapontos que se dispõem a este problema. No entanto, todas estas dependem, de maneira direta ou indireta do empoderamento feminino. Afinal, a independência financeira é um grande passo perante a inserção da mulher, de forma emancipada, na sociedade. Em graus, o vínculo empregatício é o primeiro passo, ainda que perseverem hoje disparidades 
salariais, assédio e outros empecilhos que brecam a autonomia feminina. No entanto, tais problemas não são reproduzidos em um ambiente em que a mulher está no topo da hierarquia profissional. De acordo com o SEBRAE (2019, p. 6), o empreendedorismo feminino cresceu 34\% de 2000 a 2014.

Destaca-se, reiterando a importância do empoderamento feminino, a declaração de 2015 da Organização das Nações Unidas (ONU) reiterando-o como um dos objetivos para o milênio, tal qual na Agenda 2030. Os princípios estabelecidos demonstram fatores que diminuem a disparidade de gênero no âmbito trabalhista, como o estabelecimento de papéis de liderança para mulheres, a promoção da educação e apoiar o empreendedorismo de mulheres de maneira colaborativa.

Ainda assim, é preciso destacar que o que se observa no empoderamento feminino, ainda é desigual. Empoderar a mulher através do trabalho faz parte do projeto de inclusão, mas não recorre ao resultado esperado de imediato, se colocando apenas como um meio, e não um fim. E isto se dá ao fato da mulher acumular tarefas não relacionadas à sua profissão.

Rowlands (1997) apresenta que o conceito de empoderamento na América do Sul e Central se dá, através da chegada do feminismo, ao trazer à tona pautas progressistas de equiparação dos sexos, analisando as estruturas sociais que compõem determinada sociedade. Ainda assim, é salientado novamente por Rowlands (1995, p. 103) que as relações econômicas do empoderamento feminino através do trabalho ainda são um fardo a mais na rotina feminina, adicionando o papel de empreendedora ou colaboradora aos de papéis de mãe ou dona de casa, por exemplo, deixando precária a condição de foco em pelo menos uma das atividades.

Dessa maneira, fica explícita a necessidade de adequar estratégias e projetos de empoderamento de acordo com as diferentes relações sociais compostas em determinada sociedade. Os processos, portanto, não podem seguir de maneira linear e serem aplicados a todas as seções econômicas e raciais, sendo cada uma promovida de forma individualizada para determinado grupo (LEÓN, 1997).

Indo adiante, é preciso complementar aliando o desenvolvimento da autonomia com processos sociais e políticos, visando a inserção e equiparação total 
de gênero. É preciso haver a inserção social da mulher através do estudo formal, da graduação, do acesso à informação, para que haja seu empoderamento de maneira ativa, não como um objeto de benefício. Hoje é possível observar tal inserção social da mulher no Rio de Janeiro, ainda que esteja interligada ao ambiente familiar ou conjugal. Sendo assim, a mulher obtém acesso à informação e percebe sua aquisição de habilidades, mas ainda permanece acorrentada à uma relação de poder.

De caráter político, ainda, é preciso destacar a representatividade feminina, tanto no ambiente dos poderes, executivo, legislativo e judiciário, como em cargos de liderança e poder no setor privado. Existe a tendência de crescimento, ainda que pequena. Tal processo acompanha o processo de empoderamento. Processo este que compõe uma participação efetivamente ativa de aquisição de espaço em todos os meios, que precisa ser destacado, é um projeto que só pode ser trabalhado de maneira conjunta com o indivíduo a ser empoderado. 0 empoderamento não é um benefício, é a conscientização do ser de que seu local de ocupação não é mais subjugado (SCHIAVO; MOREIRA, 2005).

Portanto, de maneira análoga, destacam-se a importância da emancipação feminina nos âmbitos profissional-econômico, social e político. Sendo o primeiro através do emprego ou empreendimento, o segundo através do acesso à informação e escolaridade e, por fim, o político, através da representatividade e tomada de decisão, ao mostrar que o lugar de liderança também pode ser ocupado por uma figura feminina.

Quanto a isso, é possível menciona que "o esforço no sentido de libertar as mulheres da dominação [...] não se pode se dar sem um esforço paralelo no sentido de liberar os homens dessas mesmas estruturas que fazem com que eles contribuam para impô-la." (BOURDIEU, 1999, p. 136).

\section{EMPREENDEDORISMO SOCIAL E ECONOMIA SOLIDÁRIA}

Como previamente abordado, destacou-se a relevância do empreendedorismo ao promover a condição de liderança e emancipação profissional da mulher. Dentro disso, é preciso destacar que, o atual sistema em vigor pressupõe 
a valorização do capital acima do trabalho, tendo por fim não a produção, mas o lucro. No entanto, existe uma alternativa a este sistema, a economia solidária, que se pauta em desenvolvimento pessoal e profissional através do trabalho, de maneira colaborativa e cooperativa, visando interesses comuns entre vários atores (VIEITEZ, 1999). Dessa maneira, conecta-se diretamente a condição de empreendedorismo social. Com destaque para as suas características principais: é coletivo e integrado; produz bens e serviços para a comunidade local e global; tem o foco na busca de soluções para os problemas sociais e necessidades da comunidade; sua medida de desempenho são o impacto e transformação social; visa resgatar pessoas da situação de risco social e promovê-las, a gerar capital social, inclusão e emancipação social. (SILVA et al., 2012)

Percebe-se, portanto, de maneira singela, uma enorme conexão das características do empreendedorismo social com as necessidades que o empoderamento social (e feminino) demanda. Tal condição não se dá ao acaso, quando se percebe que o empreendedorismo social se dá ao olhar para determinado grupo social que foi marginalizado e precisa ser inserido de maneira sólida e igualitária em determinado setor da sociedade. Marginalização essa que foi presente na vida das mulheres e vêm sendo moldada para que desapareça, principalmente através do empoderamento.

Com os preceitos do empreendedorismo social e da economia solidária definidos, é possível perceber que os rumos do avanço feminino se darão - como já abordados anteriormente - através da emancipação econômica, social e política da mulher. Nesse sentido, a política de linhas de crédito reforça um suporte ao empreendedorismo feminino, sendo utilizadas cada vez mais. Estratégia eficiente em diversas demandas no mundo, sendo aqui no Brasil representadas, por exemplo, pelo Pronaf Mulher. 0 empreendedorismo social demonstra, por si só, que é preciso ter seu foco voltado à transformação social de determinado grupo, visando solucionar seus problemas, nesse caso em específico, o estado de subordinação e subestimação da figura feminina.

De maneira parecida, a economia solidária propõe a colaboração de grupos em um desenvolvimento cooperativo, visando também a promoção de soluções 
integradas para problemas econômicos. Não é absurdo correlacionar os dois conceitos e, por dedução, concluir que se inserirmos as características do empreendedorismo social em um projeto de economia cooperativa, é possível promover o empoderamento de um grupo em não apenas uma coluna (a econômica), mas também nos âmbitos político e social.

Receber crédito de um banco pode ser uma opção assertiva para tornar seu negócio viável, servirá para equilibrar o fluxo de caixa de sua empresa para consagrar uma oportunidade de negócio.

O programa "Itaú Mulher Empreendedora" (ITAÚ, 2019) e o BNDES trazem linhas de crédito para as mulheres, com o plano de inspirar, sustentar, capacitar e conectar empreendedoras de diversas maneiras diferentes e para isso não mediu esforços para diversificar suas linhas, Cartão de Crédito Empresarial - Limite de crédito rotativo, para micro e pequenas empresas. Cheque especial - Limite de crédito rotativo, concedido diretamente na conta corrente, e que permite saques até o limite contratado. Caixa Reserva - Limite de crédito rotativo cujo recurso é concedido em uma conta contratual e movimentado a partir de solicitações de saque e pagamento feitas ao gerente. Antecipação de cartões - Operação realizada pelo banco com o objetivo de antecipar para o cliente o valor de seus recebíveis originados das vendas com cartões de crédito. Pode se citar outras linhas só para mulheres como do BNDES que vem dando uma autonomia para o empreendedorismo feminino onde podemos cita o Cartão BNDES - Linha de financiamento do BNDES que tem como objetivo disponibilizar crédito rotativo para micro, pequenas e médias empresas, Progeren - Linha de financiamento do BNDES que tem como objetivo disponibilizar capital de giro para micro, pequenas e médias empresas, Finame - Financiamento da produção e aquisição de máquinas e equipamentos nacionais credenciados no BNDES (BNDES, 2018).

\section{CONSIDERAÇÕES FINAIS}

Com o estabelecimento das bases de desenvolvimento em patamares cooperativos e colaborativos, define-se também uma estratégia econômica generalizada. Entretanto, com a correlação deste preceito da economia colaborativa 
com o conceito de empreendedorismo social (visando, prioritariamente, o empoderamento que o empreendedorismo dispõe frente ao vínculo empregatício), é possível compreender o preenchimento de certas lacunas em ambos termos. 0 empreendedorismo social não dispõe de uma estratégia pré-definida de desenvolvimento, ainda que apresente seus objetivos e sua relação com os agentes. Por outro lado, a economia solidária promove de maneira minuciosa uma estratégia, mas não abarca soluções fora do parâmetro econômico, sem promover qualquer tipo de ação política ou social.

Ainda assim, fica explícita a proliferação do empreendedorismo feminino como apresentado nos dados - devido a diversos fatores. Isso demonstra que nesse âmbito o mercado tende a crescer, visto que mais mulheres ainda se juntarão a este modelo.

Isto se deve, acima de tudo, à ação das políticas públicas que preparam o terreno para que a semente do progresso empreendedor feminino seja plantada. Estas são as fundações de uma igualdade profissional. E, acima de tudo, é preciso não demandar demagogias por parte das instituições - sejam estas públicas ou privadas.

É preciso tomar cuidado com o assistencialismo exacerbado na proposta de impulsionar o empoderamento feminino pelo empreendedorismo. Isto é, porque, o protagonismo precisa ser da mulher e não da instituição ou órgão. 0 propósito precisa ser o desenvolvimento sustentável e a sucessão da igualdade de gêneros no meio profissional, em prol dos seus direitos e não da autopromoção.

Sendo assim, indutivamente, é possível definir uma estratégia de empoderamento feminino através da junção das duas proposições, atingindo assim o grau de maior emancipação, de forma a promover a igualdade de gêneros em todas as esferas a serem tratadas. Determinando, dessa forma, o papel vital das políticas públicas para o desenvolvimento feminino na esfera profissional e social - tal qual outras esferas, também. 


\section{REFERÊNCIAS}

BNDES. Pronaf Mulher: financiamento à mulher agricultora integrante de unidade familiar de produção enquadrada no Pronaf, independentemente do estado civil. Rio de Janeiro: BNDES, 2018. Disponível em:

https://www.bndes.gov.br/wps/portal/site/home/financiamento/produto/pronafmulher. Acesso em: 17 dez. 2018.

BOURDIEU, P. A dominação masculina. Rio de Janeiro: Bertrand Brasil, 1999.

CRUZ, C. F. Os motivos que dificultam a ação empreendedora conforme o ciclo de vida das organizações: um estudo de caso: Pramp's lanchonete. 2005. 126f. Dissertação (Mestrado em Engenharia de Produção) - Centro Tecnológico, Universidade Federal de Santa Catarina, 2005.

DYE, T. D. Understanding Public Policy. Englewood Cliffs: Prentice Hall, 1984.

ITAÚ. Itaú Mulher Empreendedora: Tipos de crédito: quais são e como usá-los. [S.I.], 11 mar. 2019. Disponível em:

https://imulherempreendedora.com.br/posts/gestao/tipos-de-credito-quais-sao-ecomo-usa-los. Acesso em: 31 out. 2018.

LEÓN, M. El empoderamientoenlateoría y prácticadel feminismo. Bogotá: Universidad Nacional de Colombia, 1997.

LYNN, L. E. Designing Public Policy: a Case book on the role of policy analysis. Santa Monica, Calif: Goodyear, 1980.

ORGANIZAÇÃO DAS NAÇÕES UNIDAS. O que é a agenda 2030? [S.I]: ONU, 2015. Disponível em: https://gtagenda2030.org.br/agenda-pos-2015/. Acesso em: Acesso em: 18 dez. 2018

ROWLANDS, J. Empoderamiento y mujeresruralesen Honduras: un modelo para eldesarrollo. Poder y empoderamiento de lasmujeres. Bogotá: Universidad Nacional de Colombia, 1995.

ROWLANDS, J. Empowerment Examined. Development in Practice, [S.I.], v. 5, n. 2, p. 101-107, 1997. Disponível em:

http://dx.doi.org/10.1080/0961452951000157074. Acesso em: 31 out. 2018.

SCHIAVO, M. R.; MOREIRA, E. N. Glossário Social. Rio de Janeiro: Comunicarte, 2005.

SEBRAE. Empreendedorismo feminino como tendência de negócios.

Salvador: SEBRAE BA, 2019. Disponível em: 
http://m.sebrae.com.br/Sebrae/Portal\%20Sebrae/UFs/BA/Anexos/Empreendedorism o_feminino_como_tend\%C3\%AAncia_de_neg\%C3\%B3cios.pdf. Acesso em:

SILVA, F. P. et al. Empreendedorismo Social. Revista Facmais, [S.I.], v. 2, n. 6, p. 104-111, 2012.

STROBINO, M. R. de C.; TEIXEIRA, R. M. Empreendedorismo feminino e o conflito trabalho-família: estudo de multicasos no setor de comércio de material de construção da cidade de Curitiba. Revista de Administração, São Paulo, v. 49, n. 1, p. 59-76, 2014. Disponível em:

https://www.redalyc.org/html/2234/223430155006/. Acesso em: 18 dez. 2018.

VIEITEZ, C. G. Economia solidária e o desafio da democratização das relações de trabalho no Brasil. São Paulo: Arte \& Ciência, 1999. 